\title{
PD-L1 serves as a double agent in separating CVL from GVHD
}

\author{
Todd V. Brennan' and Yiping Yang ${ }^{2,3}$ \\ 1Department of Surgery, ${ }^{1}$ Department of Medicine, and ${ }^{3}$ Department of Immunology, Duke University Medical Center, Durham, North Carolina, USA.
}

\begin{abstract}
Allogeneic hematopoietic cell transplantation (HCT) represents a potentially curative treatment for a variety of hematologic malignancies due to the well-recognized graft-versus-leukemia/lymphoma (CVL) effect that is mediated by donor-derived alloreactive T cells. However, graft-versus-host disease (CVHD) is mediated by the same T cells and remains a significant clinical problem associated with substantial morbidity and mortality. In this issue of the $J \mathrm{Cl}, \mathrm{Ni}$ and colleagues used several murine models of CVHD to evaluate the effect of $C D 4^{+} T$ cell depletion on $\mathrm{CVL}$ versus $\mathrm{CVHD}$ and revealed that depletion of $\mathrm{CD4}{ }^{+} \mathrm{T}$ cells leads to the upregulation of $\mathrm{PD}-\mathrm{L} 1$ by recipient tissues and donor CD8 ${ }^{+}$T cells. Interaction of PD-L1 with PD-1 in CVHDtargeted tissues resulted in $\mathrm{CD8}^{+} \mathrm{T}$ cell exhaustion and apoptosis, thereby preventing CVHD, whereas PD-L1 interactions with CD80 in lymphoid tissue promoted CD8+ $T$ cell survival and expansion, thereby enhancing the GVL response. By separating these seemingly similar alloreactive $T$ cell responses based on the context of interaction, the results of this study may lay the groundwork for the development of effective clinical strategies to enhance GVL while minimizing CVHD following allogeneic HCT.
\end{abstract}

\section{GVL versus GVHD}

For a variety of hematologic malignancies, including acute and chronic leukemias and lymphomas (1), allogeneic hematopoietic cell transplantation (HCT) can be a potentially curative therapeutic strategy. Allogeneic HCT can benefit these malignancies due to the well-recognized graft-versus-leukemia/lymphoma (GVL) effect that is mediated by donor-derived alloreactive $\mathrm{T}$ cells. Unfortunately, these same $\mathrm{T}$ cells are also responsible for graftversus-host disease (GVHD) (2), which results in significant morbidity and mortality. While depletion of $\mathrm{T}$ cells from donor allografts prevents GVHD, removal of these cells results in increased graft failure and increased rates of tumor relapse. Similarly, immunosuppressive agents used to prevent or treat the pathologic GVHD response also reduce the beneficial GVL response.
The difficulty in separating GVL from GVHD rests in the underlying similarity of the alloreactive $\mathrm{T}$ responses behind both processes. Over the past decades, tremendous efforts have been made to identify specific immune mechanisms underlying GVL versus GVHD in order to separate them. Several promising clinically applicable approaches have been identified for promoting GVL and reducing GVHD, including depletion of subpopulations of GVHD-associated donor naive $\mathrm{T}$ cells, selection of GVL-maintaining memory T cells $(3,4)$, administration of donor NK cells that provide GVL without GVHD (5, 6), and, more recently, the use of allogeneic chimeric antigen receptor $T$ cells that target tumor cells with limited capacity for GVHD induction (7). Furthermore, GVHD occurs primarily in parenchymal tissues, such as liver, skin, and intestine, whereas

\section{Related Article: p. 1960}

GVL targets hematologic tumors in the lymphoid tissue, such as lymph nodes and spleen, and the bone marrow; therefore, strategies to separate GVL from GVHD based on their differences in tissue microenvironment that may affect alloreactive $\mathrm{T}$ cell responses are desirable to explore.

\section{Role of PD-L1 in separating GVL from GVHD}

Programmed death ligand-1 (PD-L1) was originally discovered as a B7 homo$\log$ that costimulated $\mathrm{T}$ cell proliferation and cytokine production (8). However, PD-L1 is best characterized by its immune inhibitory function as a result of PD-L1/ programmed death-1 (PD-L1/PD-1) interactions between antigen-presenting cells and $\mathrm{T}$ cells that result in $\mathrm{T}$ cell exhaustion and apoptosis $(9,10)$. As PD-1 is highly expressed by tumor-infiltrating lymphocytes and PD-L1 is expressed by many tumors (11), engagement of PD-L1/PD-1mediated inhibition offers an immune checkpoint by which tumors can evade the host immune response $(12,13)$. Multiple clinical trials have evaluated the ability of mAbs that target the PD-L1/PD-1 interactions that are inhibitory to $\mathrm{T}$ cells to increase the tumoricidal properties of tumor-infiltrating T cells $(14,15)$.

While many studies have focused on the inhibitory functions of PD-L1, other reports have demonstrated that $\mathrm{PD}-\mathrm{L} 1$ is important for $\mathrm{T}$ cell proliferation and cytokine production $(8,16)$, leading to the hypothesis that, in addition to PD-1, another PD-L1-binding partner existed (17). Shortly thereafter, CD80 was identified as a binding partner for PD-L1 by expression cloning using a cDNA library prepared from $\mathrm{Cd} 28^{-/-} \mathrm{Ctla}-4^{-/-} \mathrm{T}$ cells (18). For CD $4^{+}$ $\mathrm{T}$ cells, PD-L1/CD80 interactions inhibit proliferation and cytokine production (18), but the opposite appears to be the case for $\mathrm{CD}^{+} \mathrm{T}$ cells. For example, PD-L1 has been shown to play a critical costimulatory role for antigen-specific $\mathrm{CD} 8^{+} \mathrm{T}$ cells during microbial infection as well as for protective 


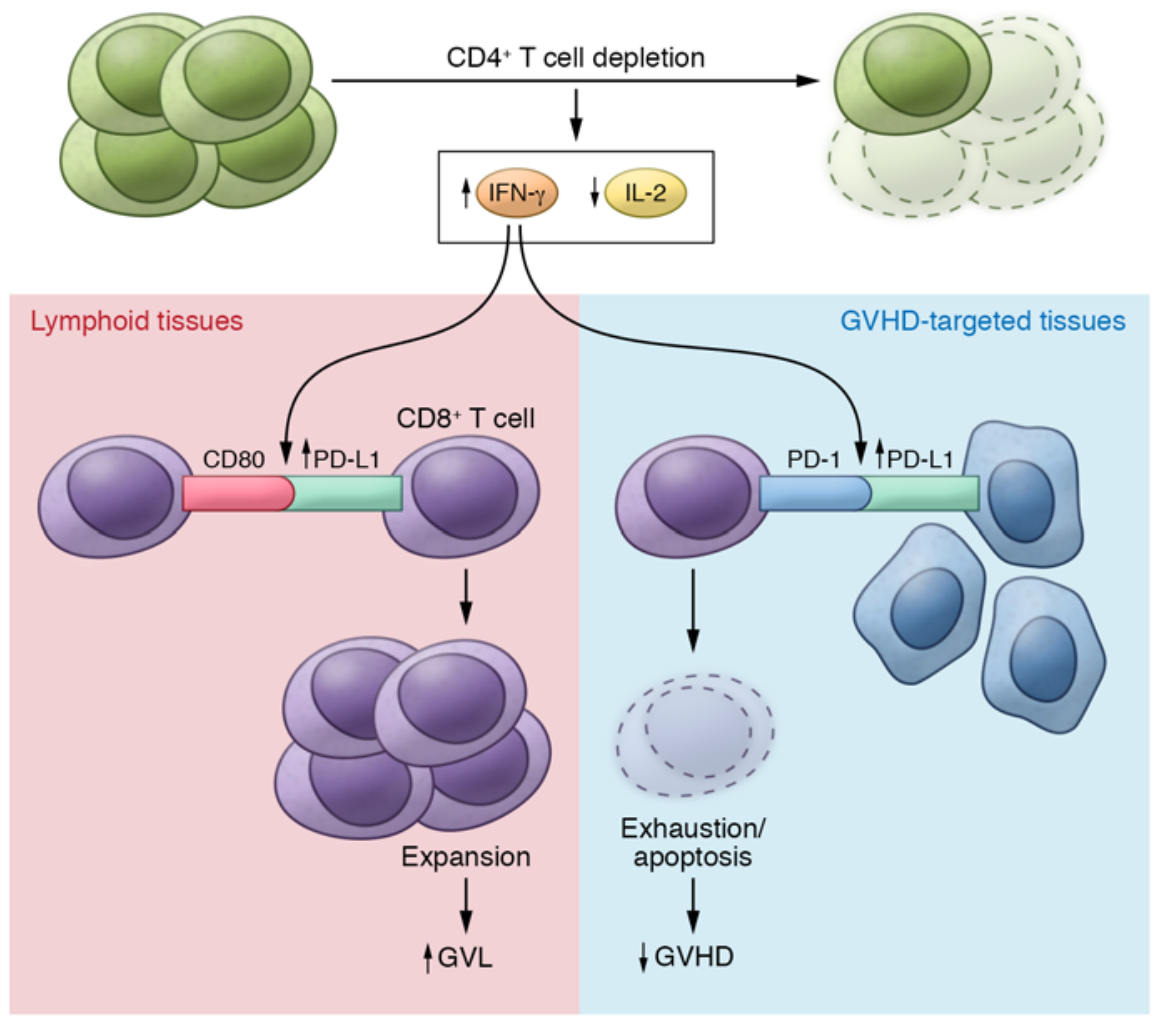

Figure 1. The effect of CD4 ${ }^{+} \mathrm{T}$ cell depletion on GVL versus GVHD. Depletion of CD4+ $\mathrm{T}$ cells following allogeneic hematopoietic cell transplantation (HCT) increases systemic levels IFN- $\gamma$ and decreases IL-2. The changes in these cytokines in turn promote expansion of CD8+ $T$ cells in lymphoid tissue with the capacity to target malignant host cells via PD-L1/CD80 interactions. Conversely, in GVHD-targeted tissues, CD4 ${ }^{+}$T cell depletion enhances the interaction of PD-L1/PD-1 interactions between $C D 8^{+} T$ cells and cells of GVHD-targeted tissues, thereby increasing exhaustion and apoptosis of host-attacking $\operatorname{CD} 8^{+} T$ cells.

immunity against infection with Listeria monocytogenes (19) and Salmonella (20). It has also been shown that PD-L1 expression by activated antigen-specific $\mathrm{CD} 8^{+} \mathrm{T}$ cells is required for their survival following expansion through both the inhibition of apoptotic $\mathrm{T}$ cell death by increasing levels of the antiapoptotic protein BCL-xL and by decreasing $\mathrm{T}$ cell-T cell fratricide (21). Blockade of PD-L1/CD80 interaction, as occurs in PD-1-deficient and PD-L1-deficient mice or with administration of an anti-PD-L1 mAb (clone 43H12 specifically blocks PD-L1/CD80 interaction and preserves PD-L1/PD-1 interactions), reduces phosphorylation of key signal transduction molecules in the TCR signaling and CD28 costimulatory pathways, including ZAP70, AKT, mTOR, and rpS6 (16).

In this issue, $\mathrm{Ni}$ and colleagues report that in vivo depletion of $\mathrm{CD} 4^{+} \mathrm{T}$ cells following allogeneic HCT prevents GVHD while maintaining an effective GVL response (22). $\mathrm{Ni}$ et al. rigorously demonstrate this finding using multiple GVHD models (two murine allogeneic HCT models and a human $\rightarrow$ mouse xenogeneic HCT model) and two tumor models, including one that was previously shown to be partially resistant to the GVL effect (23). In these models, $\mathrm{CD} 4^{+} \mathrm{T}$ cell depletion increased serum IFN- $\gamma$ levels, leading to upregulation of PD-L1 in recipient tissues and donor $\mathrm{CD} 8^{+}$ T cells (Figure 1). In GVHD target tissues, $\mathrm{Ni}$ and colleagues found that increased PD-L1/PD-1 interactions between recipient tissues and donor $\mathrm{CD} 8^{+} \mathrm{T}$ cells led to $\mathrm{T}$ cell exhaustion and apoptosis, thereby preventing GVHD. In lymphoid tissues, enhanced PD-L1/CD80 interactions between $\mathrm{CD}^{+} \mathrm{T}$ cells augmented $\mathrm{T}$ cell survival and expansion and preserved the GVL response. Ni and colleagues concluded that the outcome of the PD-L1-mediated effect on $\mathrm{CD} 8^{+} \mathrm{T}$ cells depends on whether $\mathrm{CD} 4^{+} \mathrm{T}$ cells are present, the nature of the interacting partner expressed by $\mathrm{CD}^{+} \mathrm{T}$ cells, and the tissue microenvironment.
The data presented by $\mathrm{Ni}$ and colleagues demonstrate the importance of context-dependent function of PD-L1 in influencing donor $\mathrm{CD} 8^{+} \mathrm{T}$ cell responses during the process of GVL versus GVHD and reveal a critical role for $\mathrm{CD} 4^{+} \mathrm{T}$ cells in regulating these processes. A context-dependent function of PD-L1 was also recently described by Saha et al. (24), who found that GVHD was reduced in mice receiving $\mathrm{Pdl1}^{-/-}$donor cells but that the GVL response was maintained. $\mathrm{Ni}$ and colleagues added to this finding by demonstrating that PD-L1/CD80 interactions are critical to the GVL effect. More importantly, Ni et al. have provided an exciting and translatable strategy that involves $\mathrm{CD} 4^{+} \mathrm{T}$ cell depletion in an effort to prevent GVHD but maintain an effective GVL response, thereby improving the outcome of allogeneic HCT. However, there are several unanswered questions from the study by $\mathrm{Ni}$ and colleagues that require further investigation. First, it is not clear how depletion of $\mathrm{CD} 4^{+} \mathrm{T}$ cells initially leads to increased IFN- $\gamma$ production in vivo. Ni et al. attributed the elevation of IFN- $\gamma$ production to increased $C D 8^{+} \mathrm{T}$ cell expansion in the absence of $\mathrm{CD}^{+} \mathrm{T}$ cells. However, as the IFN- $\gamma$-dependent enhancement of PD-L1/CD80 interactions between CD8 ${ }^{+}$ $\mathrm{T}$ cells is important for survival and expansion of this population, it is possible that the initial increase in IFN- $\gamma$ production in $\mathrm{CD}^{+} \mathrm{T}$ cell-depleted mice could be from other IFN- $\gamma$-producing cells, such as NK and/or NKT cells. Second, in addition to increased IFN- $\gamma, \mathrm{Ni}$ and colleagues also observed a reduction in IL-2 production in the absence of $\mathrm{CD} 4^{+} \mathrm{T}$ cells. Because $\mathrm{CD} 8^{+}$ $\mathrm{T}$ cells require IL-2 for their activation and proliferation, a potential role for reduced IL-2 production in the observed decrease in GVHD cannot be ruled out. Third, studies have shown that upregulation of PD-L1 by IFN- $\gamma$ is a local effect (15). As Ni and colleagues only showed an increase in systemic IFN- $\gamma$ levels in the absence of $\mathrm{CD}^{+}$ $\mathrm{T}$ cells, it would be important to delineate whether IFN- $\gamma$ expression is also increased within the local environment. Similarly, in addition to IFN- $\gamma$, other cytokines, such as IL-27 and TGF- $\beta$, can upregulate expression of PD-L1 $(25,26)$. Although Ni et al. found no notable differences in serum IL-27 concentrations in recipients treated with anti-CD4 mAb compared with a 
control IgG, it remains unknown whether the local levels of these cytokines can be affected by $\mathrm{CD}^{+} \mathrm{T}$ cell depletion. Last, studies have shown that PD-L1 expression on hematopoietic cells can inhibit $\mathrm{CD}^{+} \mathrm{T}$ cell numbers and function through interacting with PD-1 in response to lymphocytic choriomeningitis virus infection (27). Thus, it remains to be determined why CD80/PD-L1 interactions are predominantly utilized to promote $\mathrm{CD}^{+} \mathrm{T}$ cell expansion in the setting of lymphoma/ leukemia/allogeneic HCT. Furthermore, as PD-L1 and CD80 are both expressed on T cells, B cells, dendritic cells, and macrophages, there is potential for bidirectional interactions between B7-1 and PD-L1 on these cell types (28). Thus, the possibility that $\mathrm{CD}^{+} \mathrm{T}$ cells may interact with nonT cells via PD-L1/CD80 cannot be excluded.

\section{Clinical implications and future directions}

The ability to separate GVL from GVHD has been the Holy Grail for allogeneic HCT. The study by $\mathrm{Ni}$ and colleagues has clear translational importance, as this work identifies a strategy to achieve the GVL effect while minimizing GVHD through in vivo depletion of $\mathrm{CD}^{+} \mathrm{T}$ cells following allogeneic HCT. As depletion of donor $\mathrm{CD}_{4}^{+}$ $\mathrm{T}$ cells ex vivo did not effectively prevent GVHD in a previous human trial (29), clinical translation of this finding will require trials to evaluate the effectiveness of in vivo depletion of $\mathrm{CD}^{+} \mathrm{T}$ cells in patients following allogeneic HCT. In this regard, zanolimumab, a fully human anti-CD4-depleting $\mathrm{mAb}$, has been developed and two-phase II clinical trials have been completed to evaluate this $\mathrm{mAb}$ for treating refractory cutaneous $\mathrm{T}$ cell lymphoma (30). Alternatively, if additional studies as discussed above confirm that systemic elevation of IFN- $\gamma$ is responsible for the observed effect of $\mathrm{CD} 4^{+}$ $\mathrm{T}$ cell depletion following allogeneic HCT, a clinical trial involving the administration of recombinant IFN- $\gamma$ could be considered to prevent GVHD while preserving GVL. Interestingly, a previous report has shown that IFN- $\gamma$ has similar paradoxical effects in promoting GVL while inhibiting epithelial GVHD (31).

The observation that different tissue microenvironments regulate PD-L1/CD80 versus PD-L1/PD-1 interactions could also have potential therapeutic implications in modulating other forms of CD8-mediated pathophysiology. For example, PD-L1 has been shown to play an important role in the activation of pathologic $\mathrm{CD} 8^{+} \mathrm{T}$ cells in a murine model of colitis (32), and blocking PD-L1 was shown to be beneficial in this model. Would selective blocking of PD-L1/ CD80 interactions while preserving PD-L1/ PD-1 interactions (e.g., with anti-PD-L1 $\mathrm{mAb}$ clone $43 \mathrm{H} 12$ that specifically blocks PD-L1/CD80 interaction and preserves PD-L1/PD-1 interactions) be even more beneficial? Reciprocally, PD-L1 provides activating signals to $\mathrm{CD} 8^{+} \mathrm{T}$ cells to provide protective immunity to combat infections with L. monocytogenes (19) and Salmonella (20), and PD-L1 inhibition during these infections has a detrimental effect on protective immunity. Would selective blocking of PD-L1/PD-1 interactions or augmentation of $\mathrm{PD}-\mathrm{L} 1 / \mathrm{CD} 80$ interactions provide therapeutic benefit to the treatment of certain microbial infections?

In summary, PD-L1/CD80 and PD-L1/ PD-1 signaling reciprocally regulate $\mathrm{CD} 8^{+}$ $\mathrm{T}$ cell expansion and function. Balancing the two signaling pathways allows donor $\mathrm{CD}^{+} \mathrm{T}$ cells to mediate the GVL effect without causing GVHD. Future efforts aimed at leveraging differences in microenvironment-regulated signaling pathways may allow overlapping, yet clinically divergent, immune functions to be separated.

\section{Acknowledgments}

We thank Lauren Halligan for assisting with the illustration of Figure 1. This work was supported by NIH grants AI101263 (to TVB) and CA136934, CA186973, and CA193167 (to YY).

Address correspondence to: Yiping Yang, Department of Medicine, Duke University Medical Center, Box 103005, Durham, North Carolina 27710, USA. Phone: 919.668.0932; Fax: 919.684.9594; E-mail: yang0029@mc.duke.edu.

1. Slavin S, Naparstek E, Nagler A, Kapelushnik Y, Ackerstein A, Or R. Allogeneic cell therapy: the treatment of choice for all hematologic malignancies relapsing post BMT. Blood. 1996;87(9):4011-4013.

2. Shlomchik WD. Graft-versus-host disease. Nat Rev Immunol. 2007;7(5):340-352.

3. Chen BJ, Cui X, Sempowski GD, Liu C, Chao NJ. Transfer of allogeneic CD62L- memory T cells without graft-versus-host disease. Blood. 2004;103(4):1534-1541.
4. Zheng $\mathrm{H}$, et al. Effector memory $\mathrm{CD}^{+} \mathrm{T}$ cells mediate graft-versus-leukemia without inducing graft-versus-host disease. Blood. 2008;111(4):2476-2484.

5. Ruggeri L, et al. Effectiveness of donor natural killer cell alloreactivity in mismatched hematopoietic transplants. Science. 2002;295(5562):2097-2100.

6. Bachanova V, Miller JS. NK cells in therapy of cancer. Crit Rev Oncog. 2014;19(1-2):133-141.

7. Brudno JN, et al. Allogeneic T cells that express an anti-CD19 chimeric antigen receptor induce remissions of $\mathrm{B}$-cell malignancies that progress after allogeneic hematopoietic stem-cell transplantation without causing graft-versus-host disease. J Clin Oncol. 2016;34(10):1112-1121.

8. Dong H, Zhu G, Tamada K, Chen L. B7-H1, a third member of the B7 family, co-stimulates T-cell proliferation and interleukin-10 secretion. Nat Med. 1999;5(12):1365-1369.

9. Park JJ, et al. B7-H1/CD80 interaction is required for the induction and maintenance of peripheral T-cell tolerance. Blood. 2010;116(8):1291-1298.

10. Keir ME, Butte MJ, Freeman GJ, Sharpe AH. PD-1 and its ligands in tolerance and immunity. Annu Rev Immunol. 2008;26:677-704.

11. Chakravarti N, Prieto VG. Predictive factors of activity of anti-programmed death-1/ programmed death ligand-1 drugs: immunohistochemistry analysis. Transl Lung Cancer Res. 2015;4(6):743-751.

12. Ahmadzadeh $\mathrm{M}$, et al. Tumor antigen-specific CD8 $\mathrm{T}$ cells infiltrating the tumor express high levels of PD-1 and are functionally impaired. Blood. 2009;114(8):1537-1544.

13. Taube JM, et al. Colocalization of inflammatory response with B7-h1 expression in human melanocytic lesions supports an adaptive resistance mechanism of immune escape. Sci Transl Med. 2012;4(127):127ra37.

14. Chen L, Han X. Anti-PD-1/PD-L1 therapy of human cancer: past, present, and future. J Clin Invest. 2015;125(9):3384-3391.

15. Topalian SL, Drake CG, Pardoll DM. Immune checkpoint blockade: a common denominator approach to cancer therapy. Cancer Cell. 2015;27(4):450-461.

16. Cassady KM, Zhou J, Riggs A, Zeng D. PD-L1/ CD80 and $\mathrm{PD}-\mathrm{L} 1 / \mathrm{PD}-1$ signaling reciprocally regulate alloreactive $\mathrm{CD}^{+} \mathrm{T}$ cell glycolysis, proliferation, apoptosis, and Gvhd-inducing capacity. Blood. 2015;126(23):4282.

17. Dong H, Chen X. Immunoregulatory role of B7-H1 in chronicity of inflammatory responses. Cell Mol Immunol. 2006;3(3):179-187.

18. Butte MJ, Keir ME, Phamduy TB, Sharpe AH, Freeman GJ. Programmed death-1 ligand 1 interacts specifically with the B7-1 costimulatory molecule to inhibit $\mathrm{T}$ cell responses. Immunity. 2007;27(1):111-122.

19. Rowe JH, Johanns TM, Ertelt JM, Way SS. PDL-1 blockade impedes T cell expansion and protective immunity primed by attenuated Listeria monocytogenes. J Immunol. 2008;180(11):7553-7557.

20. Lee S-J, O’Donnell H, McSorley SJ. B7-H1 (programmed cell death ligand 1 ) is required 
for the development of multifunctional Th1 cells and immunity to primary, but not secondary, Salmonella infection. J Immunol. 2010;185(4):2442-2449.

21. Pulko V, et al. B7-h1 expressed by activated CD8 $\mathrm{T}$ cells is essential for their survival. J Immunol. 2011;187(11):5606-5614

22. Ni X, et al. PD-L1 interacts with CD80 to regulate graft-versus-leukemia activity of donor $\mathrm{CD} 8^{+} \mathrm{T}$ cells. JClin Invest. 2017;127(5):1960-1977.

23. Matte-Martone C, et al. Graft-versus-leukemia (GVL) against mouse blast-crisis chronic myelogenous leukemia (BC-CML) and chronic-phase chronic myelogenous leukemia (CP-CML): shared mechanisms of $\mathrm{T}$ cell killing, but programmed death ligands render CP-CML and not BC-CML GVL resistant. J Immunol. 2011;187(4):1653-1663.
24. Saha A, et al. Programmed death ligand-1 expression on donor $\mathrm{T}$ cells drives graftversus-host disease lethality. JClin Invest. 2016;126(7):2642-2660.

25. Carbotti G, et al. IL-27 induces the expression of IDO and PD-L1 in human cancer cells. Oncotarget. 2015;6(41):43267-43280.

26. Baas $\mathrm{M}$, et al. TGF $\beta$-dependent expression of PD-1 and PD-L1 controls CD8(+) T cell anergy in transplant tolerance. Elife. 2016;5:e08133.

27. Mueller SN, et al. PD-L1 has distinct functions in hematopoietic and nonhematopoietic cells in regulating $\mathrm{T}$ cell responses during chronic infection in mice. J Clin Invest. 2010;120(7):2508-2515.

28. Latchman YE, et al. PD-L1-deficient mice show that PD-L1 on T cells, antigen-presenting cells, and host tissues negatively regulates T cells. Proc
Natl Acad Sci U S A. 2004;101(29):10691-10696.

29. Martin PJ, et al. A phase I-II clinical trial to evaluate removal of $\mathrm{CD} 4$ cells and partial depletion of CD8 cells from donor marrow for HLA-mismatched unrelated recipients. Blood. 1999;94(7):2192-2199.

30. Kim YH, et al. Clinical efficacy of zanolimumab (HuMax-CD4): two phase 2 studies in refractory cutaneous T-cell lymphoma. Blood. 2007;109(11):4655-4662.

31. Wang $\mathrm{H}$, et al. Paradoxical effects of IFN- $\gamma$ in graft-versus-host disease reflect promotion of lymphohematopoietic graft-versus-host reactions and inhibition of epithelial tissue injury. Blood.2009;113(15):3612-3619.

32. Kanai T, et al. Blockade of B7-H1 suppresses the development of chronic intestinal inflammation. JImmunol. 2003;171(8):4156-4163. 